\title{
SEXUALIDAD RECONCILIADA: MIRADA TEOLÓGICA HACIA UN HORIZONTE ESPERANZADOR PARA VÍCTIMAS DE ABUSO SEXUAL
}

Reconciled sexuality: theological perspective towards a promising horizon for victims of sexual abuse

\author{
Anamary Mazorra VÁzQuez ${ }^{\mathrm{I}}$ \\ Carlos Ignacio Man Ging ${ }^{2}$
}

\section{Resumen}

Ante la realidad dolorosa y escandalosa del abuso sexual la Iglesia no se ha quedado callada. La profundidad de la fe cristiana ofrece posibilidades de búsqueda de justicia y de sanación integral que no puede ofrecer ni el ámbito legal ni el psicológico por sí solos. La sexualidad es una de las dimensiones humanas que más sufre con un acto de violencia sexual. Después de un abuso sexual, la víctima queda marcada para siempre, y su dimensión sexual experimenta una especie de ruptura interior; pero, jes posible para una persona abusada sexualmente, volver a gozar de una sexualidad reconciliada, integrada y madura? Si fuera el caso, ¿podría una dinámica cristiana de reconciliación dar luces o aportar en algo a su recuperación sexual? Estos son los principales interrogantes del presente estudio que originalmente forma parte de un trabajo de titulación en el campo teológico. La información compilada y ofrecida a continuación pertenece a la sección documental del mismo. En dicha revisión bibliográfica se arrojan ya resultados esperanzadores que invitan a considerar alternativas pastorales más efectivas para responder al problema del abuso sexual: primero, una sexualidad reconciliada puede garantizar una mayor capacidad afectiva del ser humano "herido y resucitado" para establecer vínculos de auténtica comunión consigo mismo, con Dios

1 Maestrante del programa de investigación en Teología de la Facultad de Ciencias Filosófico-Teológicas de la Pontificia Universidad Católica del Ecuador.

Correo electrónico: mv.anamary@gmail.com - https://orcid.org/0000-0001-5281-7520

2 Doctor en Medicina Paliativa, Ludwig-Maximilians-Universität München, Alemania. Doctor en Literatura y licenciado en Filosofía, Psicología y Teología. Decano de la Facultad de Ciencias Filosófico-Teológicas de la Pontificia Universidad Católica del Ecuador. Correo electrónico: cimanging@puce.edu.ec 
y con los otros; segundo, si una sexualidad reconciliada es fruto de una relación restaurada con Dios y con lo más íntimo de la persona, se necesitará un camino de acompañamiento integral donde la dimensión espiritual sea trabajada. Finalmente, se revela que el camino hacia la reconciliación de una sexualidad rota por el abuso es largo y complejo, por lo tanto, a) implica un esfuerzo interdisciplinar, b) no puede ser la meta prefijada de un proceso de sanación, sino un horizonte libre para las víctimas, y c) requiere un proceso de perdón.

Palabras clave: Sexualidad; Reconciliación; Justicia; Filiación con Dios; Perdón; Abuso sexual.

\section{Abstract}

In the face of the painful and outrageous reality of sexual abuse, Church has not remained silent. The profoundness of Christian faith offers possibilities for searching for justice and integral healing that could not be offered by law or psychology alone. Sexuality is one of the human dimensions that is most affected after an act of sexual violence because the victim is left with a mark on her and experiences a kind of internal breakdown. However, is it possible for a victim of sexual abuse to enjoy once again a reconciled, integral, and mature sexuality? If that were the case, could a Christian dynamic of reconciliation throw light on or contribute to her recovery? These are the question addressed in this article, which is part of a dissertation in the theological field. The information gathered and presented in this article belongs to the documentary research of that dissertation. The literature review offers promising results that encourage considering more effective pastoral alternatives to address the issue of sexual abuse: first, a reconciled sexuality might guarantee a greater affective capacity of the "hurt and resurrected" human being to establish bonds of an authentic communion with themselves, with God, and with others. Secondly, if a reconciled sexuality is the result of a restored relation with God and themselves, it might be necessary an integral counseling that includes the spiritual dimension. Finally, it is shown that the path towards the reconciliation of a sexuality broken by abuse is long and complex, therefore it a) involves an interdisciplinary effort, b) cannot be the fixed goal of a healing process, and c) requires a process of forgiveness.

Keywords: Sexuality; Reconciliation; Justice; Filiation with God; Forgiveness; Sexual Abuse.

\section{Introducción}

La realidad dolorosa de la violencia sexual, que como toda pandemia desconoce tiempos, fronteras o clases sociales, ensombrece actualmente al mundo entero y, por supuesto también al Ecuador. Especialmente en la última década, los eventos de abuso sexual se han vuelto un hecho cada vez menos silenciado, pero con gran dificultad en su tratamiento (hasta mayo de 2019, según la Fiscalía General del Estado, Ecuador contaba un total de 5700 denuncias por abuso sexual de las cuales solo una cuarta parte fue procesada). 
Los datos con los que se cuenta revelan el número creciente de niñas, niños y adolescentes víctimas de abuso sexual en el territorio nacional ${ }^{3}$.

El tema es grave en efecto, y aunque tiene nombres propios, no es aislado. Precisar el origen de la violencia sexual se vuelve muy complejo, pues, a pesar de ubicarse dentro de la clasificación de hecho de violencia directa de índole sexual, esta se enmarca en un tejido estructural y cultural que resulta igualmente violento pero indirecto e invisible. Si atendemos a esta dinámica tridimensional de la violencia, podemos afirmar que para prevenir la ocurrencia de abuso sexual, no basta con el tratamiento especializado y aislado de abusadores concretos, sino que se necesita un cambio cultural potente, una reestructuración radical que garantice dinámicas de vida no violentas o que al menos, puedan acompañar a sanar las consecuencias devastadoras del abuso sexual.

Ante un problema de tal envergadura se requieren soluciones interdisciplinarias y se necesita que todas las esferas de la sociedad aporten con lo mejor que puedan. Aunque la mayoría de académicos estudiosos del tema no consideran de importancia el ámbito espiritual y religioso, la Iglesia sí puede jugar un papel fundamental en ello, pues para muchas víctimas que han sido creyentes, la violación de su dimensión sexual causa una ruptura a nivel espiritual. Esto imposibilita luego gozar de una relación sana consigo mismo, con los demás y con Dios.

Como consecuencia, la Iglesia Católica tiene la misión urgente de replantearse los espacios de acogida y de acompańamiento a las víctimas de abuso sexual. Al iluminar el camino de sanación y de reelaboración existencial de estos sobrevivientes desde los misterios de la fe se revela que la dignidad del ser humano nace del amor creador de Dios que es gratuito e incondicional, y que este vínculo filial es el fundamento de todas las demás relaciones. También se percibe que especialmente, el misterio de la Muerte y Resurrección de Jesús puede marcar la ruta de este camino de sanación y liberación como condición de posibilidad de resurrección y reconciliación. Asimismo, se apunta cómo este camino de reconciliación a nivel espiritual requiere de un proceso simultáneo de reconciliación a nivel sexual.

Con el trabajo realizado recientemente en el ámbito eclesial a nivel nacional, podemos reconocer los pasos concretos que la Iglesia ha dado en torno a esta preocupación pastoral. Especialmente, la Facultad

3 El Centro Ecuatoriano para la Promoción y Acción de la Mujer (CEPAM) registró entre 2004-2007, 196 casos de delitos sexuales, de los cuales, un 60\% fueron incesto; "17.448 nińas menores de catorce años parieron en Ecuador entre 2009 y 2016, la gran mayoría víctimas de violación” (Acosta \& Aguilar, 2018); “desde 2008 hasta octubre de 2017, el Ministerio de Educación contabilizó 919 denuncias de violencia sexual en espacios educativos... antes de este período no existen estadísticas" (Diario El Comercio, 2018). Según la misma instancia, en 2014 se registraron 26 denuncias de delitos sexuales en el sistema educativo; en 2015 el número llegó a 79; en 2016 la cifra subió a 247; y solo de enero a octubre de 2017 sumaba 230; “en 2016, se cometieron 3.502 abusos sexuales en el Ecuador de los cuales 1.155 fueron niñas" (Ponce, 2018).

Los datos oficiales muestran que "una de cada 10 mujeres en Ecuador fueron víctimas de abuso sexual antes de los 18 años de edad” (Molina, 2018; López \& Poma, 2007; Cerón-Hernández, Roa \& Salcedo, 2017; “el 65\% de los casos de abuso sexual a menores fue cometido por familiares y personas cercanas a la víctima” (UNICEF Ecuador, 2017). Es más, según la Federación de Mujeres de Sucumbíos, en 2016 el 66\% de los delitos sexuales cometidos en la zona fueron en contra de niños y niñas menores de 14 años; de estos, nueve de cada 10 víctimas fueron niñas, de las cuales ocho lo fueron de alguien de su entorno más cercano (Rodríguez, Arteaga \& Rodríguez, 2014). 
de Ciencias Filosófico-Teológicas de la Pontificia Universidad Católica del Ecuador se ha comprometido en dar una respuesta pertinente a dicha situación a través el Programa online de Prevención del abuso sexual de niños y jóvenes y con un proyecto de investigación del mismo nombre que recoge los aportes interdisciplinares del Centro de Psicología Aplicada, la Dirección de Informática, la Dirección de Identidad y Misión juntamente con la antes mencionada Facultad de Filosofía y Teología. Este proyecto investigativo ya ha dado frutos: algunos han sido ya publicados y otros están en camino. Dentro de este marco se encuentra el presente trabajo de investigación relacionado con una mirada teológica sobre los procesos de reconciliación para víctimas de abuso sexual durante su infancia y adolescencia. El presente artículo, entonces, recoge una parte de la discusión sobre esas claves teológicas de acompańamiento espiritual y del proceso de sanación integral de las personas abusadas.

Ahora bien, investigar un fenómeno en tal magnitud perjudicial para la humanidad desde una mirada teológica no puede derivar en otra cosa sino en un horizonte esperanzador. El Dios creador de nuestras vidas, y, por lo tanto, también de nuestra sexualidad, no cesa de crear, es decir, de amar y de dar sentido a nuestra existencia más allá de las rupturas y sufrimientos de los cuales participamos. El mismo Dios creador (Gn 1-2), todo amoroso (1Jn 4,8) en el que creemos y del cual damos testimonio, redime nuestro dolor (Ap 2,10), nos reconcilia con Él mediante su Hijo (2Co 5, 18) y nos devuelve la paz. Teniendo en cuenta esta verdad de fe ¿podemos atrevernos a considerar la posibilidad de reconciliación para víctimas de la injusticia y la violencia sexual?, ¿es posible para una persona desintegrada por el abuso sexual, volver a gozar de una sexualidad reconciliada, integrada y madura que le permita recuperar su vínculo amoroso y filial con Dios? ¿Acaso una dinámica cristiana de reconciliación puede aportar en algo a la recuperación o a la sanación de la sexualidad de un sobreviviente de abuso sexual?

La presente reflexión busca respuestas teológicamente válidas a estos interrogantes, para ello: 1) Se analizará brevemente el fenómeno del abuso sexual como ruptura con el plan amoroso de Dios, sus consecuencias y las posibilidades de recuperación o sanación para las víctimas; 2) Se explicará a qué llamamos sexualidad -sexualidad integrada, madura-, sus dimensiones, significados e importancia para la vida humana como regalo divino; 3) Se proporcionarán ciertas claves pastorales para el acompańamiento de procesos de reconciliación desde la lógica cristiana de restablecer la justicia divina en todas las dimensiones del ser humano (aquí, especialmente orientada a la dimensión sexual).

De antemano reconocemos el límite que puede presentar el tratamiento de temas tan complejos como la sexualidad, la experiencia angustiosa de las víctimas de abuso sexual y la dinámica cristiana de reconciliación en un solo artículo, pero lo hacemos con entusiasmo y responsabilidad en la tarea que exige mirar hacia el horizonte de esperanza que puede representar, para las víctimas de abuso, una sexualidad reconciliada.

\section{Abuso sexual: Definición y tipología}

De acuerdo con la Organización Mundial de la Salud (OMS, 2016) todo acto sexual o la tentativa de consumarlo, los comentarios o insinuaciones sexuales no deseados por el que escucha, o las acciones para comercializar o utilizar de cualquier otro modo la sexualidad de una persona mediante coacción por otra persona, en cualquier ámbito, incluidos la casa y el puesto de trabajo, es abuso sexual. Este es el concepto base 
aplicado internacionalmente a los códigos civiles, a las normativas de conducta y a cualquier aparato legal que tipifica el delito. Sobre él se construyen otros conceptos que incluyen, por ejemplo, las consecuencias que sufren las víctimas de este acto delictivo.

Dentro de sus clasificaciones podemos encontrar los actos sin contacto, los actos con contacto sin penetración, los actos con contacto y con penetración, y otras formas de abuso como el travestismo impuesto, el uso de la pornografía, la explotación sexual de la persona a través de la prostitución, etc. Uno de los tipos de actos con contacto y con penetración es la violación. Sobre éste, en el numeral 2356 del Catecismo de la Iglesia Católica leemos:

La violación es forzar o agredir con violencia la intimidad sexual de una persona. Atenta contra la justicia y la caridad. La violación lesiona profundamente el derecho de cada uno al respeto, a la libertad, a la integridad física y moral. Produce un daño grave que puede marcar a la víctima para toda la vida. Es siempre un acto intrínsecamente malo. Más grave todavía es la violación cometida por parte de los padres (cf. incesto) o de educadores con los niños que les están confiados.

Subrayamos aquí la idea de que no solamente la violación, sino que cualquier tipo de abuso sexual, "atenta contra la justicia y la caridad". Y la justicia, continúa explicando el mismo Catecismo (I. Católica, 2006, n.1929), "sólo puede ser conseguida sobre la base del respeto de la dignidad trascendente del hombre" y de la mujer, de todo ser humano. El abuso sexual se convierte así en un acto atroz de injusticia, pues constituye un acto de índole sexual que trasgrede la dignidad de la persona abusada.

Si profundizamos un poco en las implicaciones que conlleva un abuso sexual, encontramos la reflexión de las profesoras Karlinj Demasuere y Stéphane Loulain de la Universidad Gregoriana de Roma, especialistas en el tema. Ellas consideran importante señalar que "el abuso sexual es una transgresión a nivel sexual, que golpea a la persona muy íntimamente en su ser" (Demasure \& Joulain, s/f., p.1), pues el cuerpo - y la sexualidad- de una persona va unido a la creación de su identidad. Más adelante se verá cómo la sexualidad constituye al ser humano y cómo siendo aspecto nuclear de la persona se expresa en varios niveles (psicológico, biológico, ético-social y espiritual-trascendente) disponiéndola al encuentro amoroso, respetuoso y creativo con los otros, para dar vida. Cuando una persona es abusada en su sexualidad, su capacidad de encuentro también sufre la herida.

El Nuevo Diccionario de Teología Moral (1993, pp. 1681-1697) recuerda que una conducta sexual marcada por factores de dominio y de abuso ignora el valor del otro como sujeto para la unión interpersonal. Y esto que pudiera parecer un hecho aislado es bastante frecuente. Muchas veces tendemos a cosificar al otro, a hacerlo menos otro, más idéntico a uno mismo, y de esta manera destruimos la originalidad propia y exclusiva del otro como persona humana. Una relación sexual de este tipo no es ni auténtica, ni sana, pues el encuentro beneficia a uno en detrimento del otro, y de acuerdo con las características del encuentro que posibilita la sexualidad, no se puede construir un verdadero nosotros, si una de las partes está anulada.

En efecto, este intento de servirse del otro para la propia autorrealización destruye el germen de verdad que debe expresar la relación amorosa entre los hombres. Este es el caso del abuso sexual. En él, la sexualidad ejercida con violencia la reduce a algo inhumano, desvirtuando así el gesto del encuentro a una conducta indigna del hombre que lo fracciona. Patxi Loidi (citado en Botero, 2012, p. 166) considera que 
la actividad sexual es personal (porque nace de la conciencia libre y responsable del sujeto) y personalizante (es decir, que nos hace más personas) cuando es resultado y expresión del amor, de lo contrario, es una "estafa". En los episodios de abusos sexuales podemos identificar los ejemplos más claros de este fraude, pues, el sujeto perpetrador cosifica a la víctima haciendo de ella objeto de su placer sexual y la despersonaliza.

En todo esto hay un detalle importante que no queremos olvidar: el tema del pudor sexual. Vidal (1991, p. 335) aclara que se basa principalmente en el derecho a la intimidad personal frente a un exhibicionismo exagerado. Este "nosotros" permite alcanzar el "equilibrio perfecto entre la intimidad personal y la apertura social". Ahora bien, cuando el hombre es vulnerado en su intimidad (Navarro, 2015), aparece en él un sentimiento de confusión, que nace del pudor herido. No en vano, un elemento común en los relatos de víctimas de abuso sexual es justamente la confusión. Cuando la persona abusada ha sido menor de edad la confusión suele ser más grande, pues a estas edades todavía se está formando el concepto de lo íntimo y lo público en su aspecto sexual.

\section{Algunas consecuencias del abuso sexual. La experiencia de ruptura fundamental}

Hemos hablado de herida, pero, ¿qué es la herida sino una ruptura dolorosa de algún lugar del cuerpo vivo? La herida que deja en los cuerpos y los corazones de las víctimas el abuso sexual es una realidad triste de ruptura que "fragmenta" a la persona, a su sexualidad, a su propia concepción de ser sexuado, digno, valioso. La ruptura provocada por un abuso sexual, al quebrantar el equilibrio de la víctima ${ }^{4}$ en los niveles antes mencionados, también desequilibra los significados positivos que tiene la sexualidad para la persona (la posibilidad de hacer comunidad de amor, la construcción universal del nosotros, la procreación y formación de una familia, la creatividad social relacional, el placer, la madurez personal).

Sabemos, por los testimonios de tantas víctimas, que muchas veces después de la transgresión ellas se sienten manchadas, sucias y, en consecuencia, se avergüenzan y se sienten indignas. En la mayoría de los casos estas secuelas son imposibles de evadir, por ello podríamos preguntar con la voz del Papa Francisco (2016, n.153):

¿Acaso se pueden ignorar o disimular las constantes formas de dominio, prepotencia, abuso, perversión y violencia sexual, que son producto de una desviación del significado de la sexualidad y que sepultan la dignidad de los demás y el llamado al amor debajo de una oscura búsqueda de sí mismo?

No es posible ignorarlas, pues la gravedad de la ruptura que provoca el abuso sexual es capaz de desintegrar a las víctimas, muchas veces, sin esperanza de sanación.

Algunas consecuencias psicosociales del abuso sexual suelen ser: impotencia, pérdida de confianza, silencio, vergüenza, culpabilidad o "deseo de desaparecer" (Demasure \& Joulain, s/f. p.3). Sabemos también

4 Por cuestión de tiempo, espacio y para no disociarnos del tema, no entraremos en discusión con las rupturas que el victimario también sufre. No obstante, vale anotar que el agresor es una persona, que, por la mala utilización de la sexualidad propia y ajena, muestra en sí secuelas de profundas heridas personales. 
que las consecuencias psicológicas a corto plazo pueden aparecer en forma de estrés, trastorno o reacción aguda ("shock"). A menudo se puede observar un trastorno postraumático a mediano-largo plazo, o una mayor probabilidad de otros síntomas psicológicos tales como depresión, pensamientos suicidas, trastornos de ansiedad, uso de sustancias psicotrópicas, trastornos del sueño, trastornos de alimentación, trastornos sexuales, entre otros. Estas perturbaciones pueden persistir durante años, y suelen perdurar durante la edad adulta (Finkelhor, 1986; Finkelhor \& Browne, 1986; Wilson 2010; OMS, 2002; Lameiras, 2002; Merlyn, 2005; Urra, 2007; López, 2009; López, 2014; Baita y Moreno, 2015; AA.VV., 2016; Coello, 2017).).

Hay una consecuencia de la que no hablan estos especialistas, anotada por Monseñor Tagle en su intervención del 21 de febrero de 2019, a saber, el resentimiento. Para el cardenal este podría considerarse como una especie de enfermedad "que infecta lenta pero inexorablemente a las personas hasta matar su entusiasmo y su energía”. Mientras más tiempo pasa sin hacerse nada al respecto, la víctima de un abuso sexual tiende a desarrollar un estado de estrés mantenido que le puede acarrear crisis muy severas en otros ámbitos de la vida privada y social. Estos y muchos otros síntomas como la ansiedad, la depresión y una autoestima muy baja son conflictos que provienen de la fractura que ha provocado el abuso sexual en una persona agredida.

Pero aquí nos detenemos en al menos una consecuencia que nos atrevemos a llamar "experiencia de ruptura fundamental", pues contiene dentro de ella las demás secuelas brutales del abuso sexual, a saber, la sensación de haber perdido la propia dignidad, y con ella, la pseudo-certeza de haber perdido el sentido de la vida. La intensidad con que se percibe la herida depende de muchos factores, por lo que quizá, para algunas víctimas esto no se manifieste tan evidentemente mientras que para otras sí (Gre Altermatt, 2019).

Sin lugar a dudas, el abuso sexual provoca una especie de desequilibrio no solo a nivel sexual, sino que, al ser un acto en que el agresor desconoce la autonomía y valor de la persona abusada, también "desordena" los significados positivos que ella tiene sobre su propia existencia. Esto provoca una sensación malsana de ser objeto en vez de sujeto, de no poder actuar en libertad, de haber sido incluso cómplice de su propio agresor, de no tener derechos a reclamar por la justicia o de recuperación de esa humanidad, libertad, autonomía y respeto que sabemos, por la fe, todos hemos recibido de manera gratuita y por puro amor de nuestro Creador.

Es más, si se dañan la dignidad de una persona y su vocación para el amor (entendido como la capacidad de entrega generosa para la construcción positiva de la vida propia y la de los demás), necesariamente la familia se rompe (porque, al menos en algunos casos, las familias sufrirán la injusticia cometida contra uno de sus miembros, si no, en la mayoría, será un miembro de la misma familia quien habrá "sepultado" la dignidad de su víctima y pariente). También la sociedad se quiebra (las normas elementales de convivencia amorosa son violadas arbitrariamente para conseguir la "satisfacción" de unos a costa del sufrimiento de otros). Sin duda alguna, mientras exista en el mundo una sola víctima de abuso sexual, ni su familia, ni su entorno social habrán alcanzado la completa humanidad, y la humanidad toda quedaría rota.

Es por ello que cuando hablamos sobre las consecuencias fundamentales del abuso sexual, inmediatamente pensamos en la imagen de una sexualidad "rota" que a su vez, va mucho más allá de un daño visible a la genitalidad de la víctima, pues implica también la dignidad herida que se convierte en humanidad quebrada, en sufrimiento inmerecido, en sociedad injusta. Recomponer entonces la 
vida de las personas abusadas se convierte en una tarea urgente y fundamental de búsqueda de justicia. Recomponer, como sinónimo de restaurar, de restablecer el equilibrio de su vida entera, ¿podríamos decir, "de reconciliar"? Es decir, recomponer a la persona en su integridad a través de la reconciliación en su dimensión afectivo-sexual. Esta es quizá la dimensión humana que más sufre con un acto de violencia sexual, la que experimenta en primer lugar una especie de ruptura interior. A continuación intentaremos responder a las siguientes preguntas: ¿En qué consiste realmente un proceso de reconciliación a nivel sexual? ¿En qué sentido esta sexualidad reconciliada tiene que ver con una experiencia de fe?, y ¿Hhasta qué punto una mirada teológica sobre este proceso puede tomarse como horizonte esperanzador para víctimas de abuso sexual?

\section{Reconciliación, una redefinición necesaria}

En la carta del Papa Benedicto XVI (2016) dirigida a los católicos de Irlanda solicitaba a los sacerdotes y religiosos con vehemencia: "Os pido, sobre todo, que seáis cada vez más claramente hombres y mujeres de oración, siguiendo con valentía el camino de la conversión, la purificación y la reconciliación”. Sin desconocer y valorar el signo salvífico del acto sacramental de la penitencia, la reconciliación implica una dimensión integradora de la vida ofendida en mayor amplitud, es decir, en un horizonte de esperanza. No sería lógico y menos aceptable proponer a las víctimas de abuso sexual un proceso de "arrepentimiento y confesión" de un pecado que ellos no han cometido. La sexualidad reconciliada, por lo tanto, se refiere a un proceso más profundo de reconstrucción, recomposición, y sanación.

La reconciliación es un término polisémico difícil de definir desde una sola interpretación. Paradójicamente, esta categoría que alude a la "unión" o "conciliación" no cuenta con un consenso entre los diferentes autores y tampoco entre las ciencias que del mismo hacen uso. No hay dudas de la afirmación de Galtung al respecto. El politólogo precisa el término como "un tema con hondas raíces psicológicas, sociológicas, teológicas, filosóficas y profundamente humanas - y nadie sabe realmente cómo materializarlo-...” (Galtung 1998, p.77). Por ello no es de extrañar que en el ámbito de la reconciliación el trabajo haya sido multidisciplinario desde siempre. Cada uno de los campos del conocimiento que ha trabajado y continúa laborando en el tema aporta algo valioso al significado del vocablo. Todavía más, dentro de una misma ciencia podemos encontrar que el uso de la reconciliación puede ser bastante disímil aunque no excluyente. De modo que, más allá de las diferencias de enfoque, se cuenta con una categoría semánticamente muy rica. Como consecuencia, se impone el deber de aclarar, dentro de la pluralidad interpretativa con que contamos, aquella que más se acerca al contexto y fin de la presente investigación.

Recordemos que desde la raíz latina del verbo, re-con-ciliare significa llamar (ciliare) juntos (con) otra vez (re) a las partes que han sido divididas injustamente, violentamente; y que es una experiencia de restablecimiento de relaciones justas. Para los hombres y mujeres de fe, estas relaciones justas tienen su origen en un vínculo fundamental, el vínculo primero con Dios Creador, a través del cual somos personas capaces de amor, de entrar en relación amorosa con Él y con los demás. El Catecismo de la Iglesia (n.357) así lo expresa: 
"Por haber sido hecho a imagen de Dios, el ser humano tiene la dignidad de persona (...) Es capaz de conocerse, de poseerse y de darse libremente y entrar en comunión con otras personas; y es llamado, por la gracia, a una alianza con su Creador, a ofrecerle una respuesta de fe y de amor que ningún otro ser puede dar en su lugar".

Desde la fe, establecer o restablecer cualquier tipo de relación “justa”, sana y amorosa implica, en primer lugar, hacer justicia con lo que somos fundamentalmente, hijos de Dios, imagen y semejanza suya. Desde esta experiencia trascendente y original de hijos amados, creaturas capaces de amar a imagen de su Creador, es posible relacionarse con justicia, es decir, con libertad, responsabilidad y respeto tanto consigo mismo como con los demás.

Este vocablo, que implica todo un proceso complejo y liberador, es reconocido por las Ciencias Sociales como camino propicio para la transformación positiva de conflictos. Johan Galtung, el padre de las nuevas teorías de paz, reconoce cómo el modo de proceder para alcanzar la justicia y la paz exige, ante todo, una comprensión adecuada del conflicto (ahondar en la comunicación de las partes divididas) para luego emprender el camino de la reconciliación verdadera con la finalidad de parar así la espiral siempre creciente de la violencia.

Si bien la comprensión sociológica de la reconciliación se realiza generalmente para contextos sociales en conflicto armado, esta podría dar luces al tipo de proceso que estamos intentando definir. En el caso específico de una víctima de abuso sexual se podría decir, convergen un conjunto de conflictos ${ }^{5}$. En primer lugar, el conflicto interpersonal en donde hay un enfrentamiento directo con el agresor, se ha cometido una injusticia grave y se produce una ruptura entre ellos. Cuando el victimario ha violentado a su víctima, ya se ha roto la relación justa a la que estaban llamados como seres humanos iguales, y desde la fe, como hijos de Dios y hermanos. En segundo lugar, está el conflicto intrapersonal, en donde se enfrentan las autovaloraciones, concepciones y creencias propias. Cuando la víctima ha sido abusada, esta experiencia de poder-sometimiento a todos los niveles es tan devastadora, que sus concepciones sobre sí misma, sobre su sexualidad, sobre su valor y dignidad, vacilan.

Cuando alguien desconoce en el otro su libertad de decisión como parte ineludible de su humanidad, le cosifica, quitándole así todo valor como sujeto libre y autónomo. Desde la fe, la experiencia es aún más desgarradora, porque además del conflicto puramente humano, sexual y psico-afectivo, entran en duda las creencias religiosas que alguna vez sostuvieron a la persona: ¿no se supone que somos todos hermanos, que estamos llamados al amor, que debemos cuidarnos unos a otros, que somos imagen de Dios? Y así tantas preguntas: ¿`soy hijo amado de Dios o soy una "cosa" manipulable?, ¿merezco ser llamado hijo después de esto?, ¿dónde estuvo Dios?, ¿por qué permitió que esto ocurra?, ¿Él lo ha deseado, realmente es para mi bien?, ¿por qué me pone esta prueba? Se produce así una ruptura también con Dios. Se quiebra el vínculo original y fundante del amor creador y gratuito que le dignifica como persona, que le hace vivir como hijo amado del Padre. Se rompe así también su capacidad de auto relacionarse desde el amor, es decir, con

5 Al seguir la teoría de Galtung también asumimos su postura de que no todos los conflictos son negativos, y que finalmente, los conflictos no se eliminan, sino que se transforman positivamente. Sin embargo, en este caso, cuando hablamos de conflicto nos referimos a los conflictos antagónicos, en los que las partes en cuestión están divididas y enfrentadas por intereses y fuerzas contrarias. 
justicia, auto respeto y libertad. La violencia que ha sufrido una persona en su dimensión sexual, deriva en una experiencia profundamente violenta a nivel psicológico y también a nivel espiritual (Odriozola, de Corral Gargallo \& Andrés, 2004).

Las partes divididas en el conflicto interno que experimenta una víctima de abuso sexual son quizá más difíciles de poner en diálogo, pues el conflicto aquí ocurre a nivel consciente y también inconsciente. Para transformar positivamente este conflicto interior se precisa un acompañamiento calificado con especialistas en las ramas de la psicología, incluso de la psiquiatría en muchos casos y de la espiritualidad. La tarea de establecer un diálogo entre las partes (o las voces) que al interior de la víctima se enfrentan es necesaria para comprender adecuadamente el conflicto que experimenta. Esta labor es ardua pero imprescindible para sanar la herida sufrida, para restaurar aquello que se ha roto injustamente dentro de sí, para reconciliar-se verdaderamente y detener, como dice Galtung, la dinámica siempre creciente de la violencia.

El Diccionario de la Real Academia Española de la Lengua (2020) recoge algunas definiciones del término no muy distantes de su sentido original y más relacionadas con el mundo religioso. A continuación algunas de ellas: "2. Restituir al gremio de la Iglesia a alguien que se había separado de sus doctrinas"; mientras que otras difieren mucho: "3. Oír una breve o ligera confesión ...; 5. Confesarse, de algunas culpas ligeras u olvidadas en otra confesión que se acaba de hacer...” Estas últimas, enunciadas así, limitan el significado más profundo que sabemos tiene el sacramento de la Iglesia católica al que llamamos reconciliación, penitencia o confesión. La reconciliación, ya sabemos entonces, que desde la tradición cristiana sacramental tiene que ver con la gracia de Dios donada a los pecadores arrepentidos. Con su perdón gratuito, Dios restablece la relación filial entre él y su creatura, y con ella vuelve a establecer la unidad y la paz personal y eclesial (Rahner, 1964). Desde este enfoque se reconocen dos dimensiones inseparables que remiten a la etimología del término: la personal (Dios y yo) y la social, o, en este contexto, eclesial (Dios, los otros y yo -que formamos la Iglesia). Este enfoque desde la Iglesia también le aporta una tercera dimensión al término: la trascendental.

Esta última dimensión la encontramos solamente en el ámbito religioso, de modo que los sociólogos más ortodoxos afirman que dicho enfoque solo separa y restringe la experiencia de reconciliación para el resto de la sociedad no creyente (Bloomfield, 2006). En contraste, para los creyentes, dicha dimensión expande el sentido de la reconciliación en tal magnitud que no se puede pensar en reconciliarse individual, interpersonal o socialmente sin la hondura aportada por la experiencia fundamental del misterio amoroso de un Dios reconciliador por su perdón gratuito. Esta dimensión es a la que se refiere el horizonte de esperanza al que se hizo alusión anteriormente.

Hasta aquí, tres elementos que rescatamos para definir la reconciliación a la que se invita. Primero, que es una llamada al restablecimiento de una "unidad primera" que ha sido fracturada o desintegrada a causa de la violencia; segundo, que esa "unidad primera" constituye nuestro vínculo fundamental y es nuestra relación filial con Dios todo amor; y tercero, que solo desde la recuperación de esta relación trascendente fundamental es posible un proceso de restauración de sanas relaciones intra e interpersonales. Para el creyente un proceso de sanación integral comienza por la reconciliación con Dios, y ésta, a su vez será la base sobre la cual se construya un proceso sólido de reconciliación en las otras dimensiones de la persona. 
Este modelo de transformación nos recuerda la economía misma de la Salvación, a través de la cual Dios se comunica en palabras y acciones, tocando lo más profundo de nuestros corazones para que volvamos a su seno y recuperemos la dignidad de hijos en su Hijo con la ayuda del Espíritu, es decir, nos reconciliemos con Él. Él "nos ha reconciliado consigo mismo por medio de Cristo y nos ha confiado el ministerio de la reconciliación" (2 Cor 5, 19). La necesidad de reconocer la dignidad de quien parece haberla perdido es básico en el proceso de reconciliación: estamos llamados a "participar, por el conocimiento y el amor, en la vida de Dios" y es este el fin y la "razón fundamental de la dignidad de todo ser humano" (Catecismo de la Iglesia Católica, n.356).

Participar en la vida de Dios nos exige ineludiblemente, relacionarnos como hermanos, reconciliarnos unos con otros. Pero, ¿podemos acaso pedirle a una víctima de abuso sexual que llame hermano su agresor? Si la reconciliación es ya un camino arduo y meta deseable en cualquier contexto violento, en el ámbito donde la violencia es sexual y donde las víctimas son niñas, niños y adolescentes, la dificultad del mismo aumenta. Se puede decir que esa invitación a restablecer relaciones que garantizan la unidad, la justicia y la paz entre una parte y otra, es decir, entre la víctima y el victimario, es verdaderamente una meta inexigible para cualquier víctima. En este contexto específico no se puede proponer, al menos no en primer lugar, un camino de reconciliación al estilo de aquellos que se proponen a las naciones en guerra o a comunidades en conflicto. Ni la psicología lo ofrece, ni la ley lo exige: A ningún acompañante de una víctima de abuso sexual se le ocurriría comenzar un tratamiento con la meta de que esta persona (sea un nińo o un adulto) vuelva a vivir a la casa del padre que lo ha abusado por ańos.

En este contexto de extrema vulnerabilidad se ha de andar con mucho cuidado. Un proceso de reconciliación mal entendido entraña el peligro de re-victimizar a un sobreviviente o de perpetuar una espiral de abusos que seguirían rompiendo a la persona abusada. Aquí no se pretende proponer arbitrariamente una definición del término reconciliación que de antemano choque abruptamente con las posibilidades reales de sanación de una víctima o con la posibilidad de prevenir el abuso sexual. En el contexto del abuso sexual la reconciliación puede ser un camino viable en la medida en que sea un proceso de cierre y curación: "cierre en el sentido que no se reabran las hostilidades entre víctimas y victimarios" o entre una parte y otra (dentro de sí mismos); “y curación en el sentido de rehabilitación”, de sanación de las heridas (Galtung, 1998, p.100). La reconciliación nunca podrá ser una meta obligada sino más bien un horizonte, al que se contempla con libertad y que puede hacerse realidad en la medida en que la víctima, en su pleno uso racional, así lo decida.

Como la idea de la "reconciliación" -en su sentido más generalizado- en contextos de abuso sexual resulta muy difícil de aceptar, además de compleja para explicar y aún más ardua de realizar, se hace más factible hablar y trabajar desde las dimensiones personal y trascendental de la reconciliación. En consecuencia, una definición adecuada dejaría fuera, al menos por el momento, la dimensión social ${ }^{6}$, quedando, pues, de la siguiente manera: Reconciliación es el camino y horizonte posible de restablecimiento

6 Entendiendo social como el ámbito donde la víctima puede volver a establecer una relación de respeto e igualdad con el victimario. Sin embrago, vale recordar que si deseamos plantear la posibilidad de una sexualidad reconciliada esta ya implica necesariamente una apertura al "otro" en general, no específicamente al agresor. Más adelante se profundiza en el significado y el alcance de la sexualidad como manera de entrar en relación con los otros, de modo que la dimensión social sí se tiene en cuenta, mas con las previsiones del caso. 
de la relación o vínculo fundamental con Dios mediante el cual se garantiza la unidad o integración de la persona rota por la violencia, y donde se hace justicia al recuperar su dignidad que es su identidad verdadera de hijos amados del Padre.

Pero, si la reconciliación, según la definición que hemos concluido aquí es un proceso más psicológico y espiritual, ¿por qué insistir en la dimensión sexual?, ¿por qué seguir hablando de reconciliación a nivel sexual?, ¿por qué, en contexto religioso, se hace necesario hablar explícitamente de una sexualidad reconciliada como esperanza para víctimas de este tipo de abuso?

\section{Hacia una sexualidad reconciliada}

Al contrario de lo que comúnmente entendemos, la sexualidad es una realidad que conforma y configura completamente al ser humano. No se refiere solamente a la genitalidad que forma parte de nuestro cuerpo, sino que comprende una serie de dimensiones constitutivas del ser humano. Marciano Vidal (1991), en su obra Moral de actitudes: moral del amory de la sexualidad, recuerda cómo somos seres sexuados (mujeres, varones) y cómo lo sexual es parte del núcleo del ser humano. Por ello no se hace extraño afirmar que el sexo "impregna y cualifica todas las actividades del ser humano" (Entralgo, 1961, citado en Vidal, 1991, p. 56). La sexualidad, por lo tanto, comprendida en su acepción plena, consiste en una realidad que se refleja y expresa en todas las dimensiones de la persona, desde el ámbito biofísico, psicológico y afectivo, hasta el ético y espiritual; ella es un aspecto presente y operante en la globalidad del ser (Vidal, 1991, p. 620; Pontificio Consejo para la Familia, 1995, n.13; López, 2012).

Si la sexualidad, como se ha dicho, comprende todos los ámbitos o dimensiones de la persona, entonces, para sanar a nivel espiritual, psicológico y afectivo, se ha de sanar también a nivel sexual. La reconciliación intrapersonal (que es la tipología en la que enmarcamos la reconciliación sexual), es un proceso de transformación positiva de un conflicto que no se puede dividir como se podría dividir la reconciliación más de tipo social. Esta última se define y separa de acuerdo a fronteras geopolíticas, mientras que la primera no puede hacerlo con respecto a las dimensiones del ser. La reconciliación al interior de un ser humano es un proceso integral, no es aislado ni exclusivo del ámbito o nivel en el que se trabaje. Como consecuencia, un proceso de reconciliación en la dimensión de la sexualidad de una persona estará siempre acompañado del mismo proceso a nivel biofísico, psicológico, afectivo y también espiritual.

Ahora bien, desde la concepción bíblica del hombre la sexualidad se presenta como una unidad de potencia vital gracias a la cual se encuentra constantemente en relación con Dios y con el mundo que lo rodea (Vidal, 1991, p. 66). De modo que tanto la dimensión instintiva (pulsión propia de la fuerza sexual) cuanto la humana (decisión libre y consciente de poner esa fuerza sexual en la construcción de la nueva humanidad) de la sexualidad, operan por medio del amor ${ }^{7}$. No puede quedarnos dudas de que ambas

7 El mismo Dios que creó la sexualidad puso la razón y la voluntad dentro del mismo plan creador, de modo que la sexualidad no es puro impulso indetenible y autónomo, sino que opera también bajo las opciones racionales y voluntarias de la persona 
dimensiones son preciosas, en efecto, como se ha señalado anteriormente, y la valoración del cuerpo y de la sexualidad desde el Antiguo Testamento es más bien positiva ${ }^{8}$ (Cahill \& McEvenue, 1998)

A propósito de esta visión bíblica, podemos hablar de una tercera dimensión de la sexualidad: la dimensión teológica. Al respecto, Juan Pablo II, en su Catequesis sobre el amor humano de 1985 (citado por Botero, 2012, p. 58) insiste en que, según esta dimensión, el sexo como lenguaje del amor se convierte en símbolo o sacramento de la alianza de Dios con la humanidad, de la alianza de Cristo con la Iglesia.

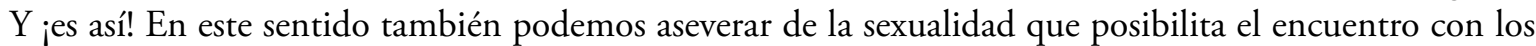
demás, que se comporta como una "puerta de salida", como un "lenguaje" o como un puente que nos empuja hacia la vida de los otros, a hacer alianza con el otro, que nos abre a los demás, que nos dispone al encuentro creativo y amoroso con el tú distinto del yo, y también con Dios como ese otro Tú trascendente que nos ha creado aptos para su encuentro. En otras palabras, la sexualidad constituye ese aspecto vital (creado) que nos permite ser y trascender en relación, posibilitando la conversión profunda de un "yo-tú" en un "nosotros" (Vidal, 1991, p. 59-63).

La vocación a este "nosotros", nos viene justamente del misterio amoroso de un Dios Trino, que no está solo, que no es un "aislado eterno", sino que es en sí mismo relación, la relación del Padre con el Hijo a través del Espíritu Santo. Asimismo, esta misma vocación relacional se sustenta sobre otro gran misterio de la fe, el de Dios encarnado en la humanidad, un Dios que asume también la sexualidad del hombre para entrar en relación amorosa con sus criaturas. De acuerdo con su carácter universal puede decirse entonces que una sexualidad vivida relacionalmente madura, es una sexualidad vivida según el deseo de Dios, al modo de relación de la Santísima Trinidad, es decir, en el amor. Una dimensión tan personal como la sexualidad, reconciliada en sí misma e inspirada en su vocación fundamental de relación amorosa con los otros, trasciende la frontera de lo meramente intrapersonal y nos ayuda a componer la instancia del nosotros-familia con la instancia del nosotros-humanidad (AA.VV., 1993, pp1681-1697; Hernández, 2008).

De aquí nace la necesidad urgente de hablar en términos de sexualidad reconciliada. Como Iglesia hemos tardado en dar respuestas claras a las víctimas de abuso sexual. No es sino hasta hace unas décadas, cuando el escándalo de las víctimas dentro del seno de la misma familia cristiana no pudo ocultarse más, el momento en el que el Magisterio comenzó a pronunciarse al respecto9 ${ }^{9}$. Este problema requiere ser tratado

8 Se puede revisar, sobre todo, los relatos de Génesis 1-2 o el Cantar de los Cantares. En estos textos encontramos que, aunque se reconocen los límites y sufrimientos de una "sexualidad rota" (humillaciones, infidelidades, dominio de los hombres sobre las mujeres, etc.), la sexualidad se presenta en su totalidad como algo querido por Dios, muy bien logrado por Él, como algo muy "bueno" (Gn, 1, 31).

9 Desde entonces no ha dejado de hacerlo, podemos ver ejemplos concretos sobre todo bajo el pontificado de Francisco. Véase, por ejemplo: 2002 - Discurso de Juan Pablo II a los Cardenales de los Estados Unidos; 2004 - Discurso de Juan Pablo II a los Obispos americanos en su visita Ad limina; 2006 - Discurso de Benedicto XVI a los Obispos irlandeses en su visita Ad limina; 2008 - Discursos y comunicados de prensa - Viaje apostólico de Benedicto XVI a los Estados Unidos de América; 2008 - Discursos y comunicados de prensa - Viaje apostólico de Benedicto XVI a Australia; 2009 - Benedicto XVI, Encuentro con la Asamblea de las Primeras Naciones, Canadá; 2010 - Discurso y Comunicado de Prensa - Viaje apostólico de Benedicto XVI a Malta; 2010 - Carta de Benedicto XVI a los católicos de Irlanda; 2010 - Carta a los Obispos de la Iglesia Católica y a los Ordinarios y Jerarcas, sobre las modificaciones introducidas en la Normae de gravioribus delictis; 2010 - Encuentro con los Obispos de Inglaterra, Gales y Escocia en la capilla de la 
mucho más profundamente de manera general, pero en la Iglesia, el tema del abuso sexual es una cuestión apremiante (Sánchez-Girón Renedo, 2020).

Si nuestra concepción de la sexualidad es sagrada y la dimensión teológica de la sexualidad nos pone frente a una responsabilidad divina y universal, entonces las consecuencias negativas sufridas a nivel sexual personal, repercuten directamente en consecuencias negativas para la humanidad. Si la sexualidad de una sola persona con rostro concreto, con nombre propio, es mal experimentada, y desde el acompañamiento que pudiera darse desde la Iglesia esta cuestión queda relegada a un segundo plano, estaremos también dejando de lado la experiencia que esa persona puede hacer de lo sagrado y su relación con Dios estaría "fracturada". Es más, si una sexualidad maltratada y abusada no se acompaña adecuadamente desde el ámbito espiritual en un proceso integral de recuperación o de reconciliación, se corre el riesgo de estar asistiendo a una construcción errónea o frágil del "nosotros-familia" y, por lo tanto, del "nosotros-humanidad".

El proceso espiritual de sanación de una víctima de abuso sexual (por supuesto, en el caso de una persona de fe) necesariamente tomará en cuenta un proceso explícito de reconciliación sexual. Esta sexualidad reconciliada, que será parte fundamental en la recuperación de su propia dignidad como hijo o hija amada del Padre deberá realizarse a su vez en al menos tres niveles: genital, psicológico, y dialógico o social. Es cierto que no podemos sacar ni de las Escrituras, ni de la Tradición, ni del Magisterio un recetario mágico que nos descubra el "paso a paso" del proceso de reconciliación sexual. Ni siquiera los tratados morales de la Iglesia serían suficientes para orientar este camino. Sin embargo, estos tres niveles de recuperación de la sexualidad herida deberán estar embarcados dentro de ese otro nivel o dimensión trascendente desde donde se comprende el plan de Dios para los hombres y las mujeres, por lo tanto, también para su sexualidad.

Botero (2012, pp. 153-159) define un camino muy claro para lograr la madurez sexual de la persona como parte del plan de Dios. El proceso de reconciliación persigue la integridad de la persona (Muñoz, 2014) e implica la recuperación de su propia dignidad. De ahí que también busca su madurez en cuanto que alcanza con ella su desarrollo completo, más pleno. Según el autor, Dios desea convertir a la sexualidad en una fuerza de unión y de explosión que da a luz la vida nueva. Con todo el significado que desentraña este deseo divino se emprendería un itinerario adecuado de reconciliación sexual. Este implicaría tanto la recuperación de la identidad sexual (primer nivel), el reconocimiento de su orientación sexual (segundo nivel), como la recomposición de su papel y función en la sociedad de acuerdo a su sexo (tercer nivel) ${ }^{10}$.

Casa Francis Martin, Oscott College (Birmingham, 19 de septiembre de 2010). Un listado más completo y actualizado encontramos en la página http://www.vatican.va/resources/index_sp.htm-\#DOCUMENTOS_PONTIFICIOS donde se guardan todos los documentos pontificios relacionados con la respuesta de la Iglesia ante los abusos sexuales.

2010- Benedicto XVI publica actualización de Sacramentorum sanctitatis tutela, la Normae de gravioribus delictis, reservada a la Congregación para la Doctrina de la Fe; 2011- Carta Circular para ayudar a las Conferencias Episcopales a elaborar líneas guía para tratar los casos de abuso sexual de menores perpetrados por clérigos; 2015-Carta Circular de la Comisión Pontificia para la Protección de los Menores a los Presidentes de las Conferencias Episcopales y Superiores de los Institutos de Vida Consagrada y Sociedades de Vida Apostólica; 2015 - Estatutos de la Comisión Pontificia para la Protección de los Menores; 2016 - Papa Francisco emite el Motu proprio "Como una madre amorosa"; Vos estis lux mundi (2019), Vademecum (16/7/2020)... Pero, ¿'es acaso suficiente?

10 Esta realidad puede cambiar de cultura a cultura, y lo que es comúnmente asignado a las mujeres en un lugar puede no coincidir con los roles asignados también a mujeres en otros contextos o culturas. Además, este es un tema con el que podríamos entrar en debate. Desde una perspectiva feminista de la teología toda la sociedad -no solamente las víctimas 
Para complementar los destinos posibles de este camino de reconciliación acogemos la propuesta de Stephan H. Pfürtner, quien apunta a los significados y fines que tiene la sexualidad madura e integrada desde una perspectiva religiosa. A los elementos ya mencionados (la realización de una comunidad de amor, la construcción del nosotros, la creación de la unidad creciente de la humanidad) el autor agrega: la procreación y formación de una familia, la creatividad social, el placer, la madurez personal, entre otras. Para el teólogo moralista alemán, la disociación de cualquiera de estos contenidos pone en peligro la sexualidad y empobrece su sentido verdadero. Podríamos agregar que ocurre lo mismo a la inversa, es decir, que una experiencia de abuso sexual disocia, daña o desintegra la sexualidad y como consecuencia, también sus fines y significados.

Podemos concluir que, en cuanto modo de relacionarse y abrirse a los otros, la sexualidad tiene como fin intrínseco el amor, más precisamente el amor como donación y acogida (Pontificio Consejo para la Familia, 1995, n.11). Es así como la sexualidad no puede ser un recurso para gratificarse o entretenerse a sí mismo, sino que, en cuanto lenguaje interpersonal donde el otro es tomado en serio, con su sagrado e inviolable valor (Francisco, 2016, n. 151) esta es puente de encuentro y de entrega a los otros. Se puede afirmar que una sexualidad madura y reconciliada en todas sus dimensiones será aquella que colabora en la obra amorosa de Dios, aquella que hace a la persona humana una criatura amanate, imagen de Dios. La verdad sobre esta vocación del ser humano ha sido revelada plenamente en el Nuevo Testamento, junto con el misterio de la vida intratrinitaria: «Dios es amor $(1 \mathrm{Jn} 4,8)$ y vive en sí mismo un misterio de comunión personal de amor (Pontificio Consejo para la Familia, 1995, n.8). La "obra amorosa" de una sexualidad reconciliada también le invita al hombre a sobrepasar sus propios límites. La persona es, sin duda, capaz de un tipo de amor superior, un amor resistente, resiliente, y resucitado; un amor que nunca se pierde, capaz de generosidad, de compasión y de perdón, semejante al amor de Dios.

Desde esta perspectiva la reconciliación a la que nos referimos es proceso y también horizonte. Especialmente para víctimas de abuso sexual, la reconciliación es el camino hacia la restauración de una justicia que tiene que ver más con la recuperación del sentido verdadero de su sexualidad (y de su vida), que con volver a establecer una relación íntima con su agresor. Esto último no podríamos ni siquiera imaginarlo, menos exigirlo. Después de sufrir la ruptura interior y fundamental que provoca el abuso sexual, la reconciliación es volver a juntar, interiormente y con la ayuda de la Gracia, esas partes sueltas que forman parte del núcleo de la vida misma, que son su germen. Reconciliar es transformar el conflicto interior de las víctimas en potencialidades para dar vida, es recuperar el sentido generoso y relacional de la sexualidad, es volver a ser (en cuanto a sentirlo, reconocerlo y agradecerlo, porque nunca dejamos de serlo en verdad) hijos dignos de un Dios que es relación amorosa. Reconciliar es recuperar la dignidad que ha sido mancillada durante el delito; es resucitar la vida que ha sido crucificada por la injusticia, por el pecado; es volver a gozar de la fortaleza bio-psico-social, ética y espiritual de la que es originalmente portadora la sexualidad.

de abuso sexual- debería replantearse el papel que han adoptado tanto las mujeres como los hombres a lo largo de la historia. Para las diversas teologías feministas hay un punto en común y este papel debe ser reconstruido e iluminado por el misterio de un Dios que es padre y también madre. 


\section{Recomendaciones pastorales para un camino de reconciliación}

Todavía quedan preguntas pendientes: ¡es acaso posible para una persona abusada sexualmente, volver a gozar de una sexualidad reconciliada, integrada? Si fuera el caso, ¿podría una dinámica cristiana de reconciliación dar luces o aportar en algo a su recuperación sexual? ¿Hasta qué punto una mirada teológica sobre este proceso puede tomarse como horizonte esperanzador para víctimas de abuso sexual? y ¿qué claves pastorales se han de tener en cuenta para ello?

Los estudios y las historias de muchas víctimas de abuso sexual durante su infancia confirman que sí, que es posible la recuperación integral de la persona. Esto, ya hemos visto, se da en diferentes intensidades y depende en gran medida de la profundidad del trauma, de los recursos psicológicos, afectivos o espirituales con los que cuenta esa persona y también del acompańamiento que recibe una vez decide emprender el camino de sanación. No encontramos cifras exactas que den cuenta de ello, pero que sea posible no significa que es fácil. La puerta hacia la reconciliación sexual, al igual que la que conduce al Reino, es angosta. El proceso de sanación suele ser complejo y largo. Volver sobre la experiencia desgarradora del abuso una y otra vez, contarla para comprenderla, comprenderla para liberarla y finalmente "soltarla" es un proceso al que no todos están dispuestos. Este es, no obstante, el único modo posible para alcanzar eso que hemos llamado una sexualidad reconciliada.

Nos queda claro que el proceso de reconciliación ha de ser un proceso acompañado. Dentro del mismo, cualquier paso debe ser dado con la mayor libertad y cuidado posible. La persona cuya dignidad ha sido rota y cuya dimensión de amor se encuentra herida, debe tratársele con mucho respeto. El camino debe ser guiado por ella misma, la toma de las decisiones, las opciones, la velocidad del proceso, etcétera, dependen de ella. Entonces, a nivel pastoral, lo único que puede hacer el acompañante es sugerir, escuchar... estar. En este caso, estar presente con los pies descalzados, ante esa persona, y escuchar su historia como si fuera un "terreno sagrado" (Ex 3, 2); y si acaso, sugerir mirar hacia un horizonte que le devuelva la esperanza. La decisión de alcanzarlo, de navegar hacia él, corresponde a la víctima. La sexualidad reconciliada se vuelve así en un horizonte y no en una meta prefijada. Pero... ¿cómo hacerlo?, ¿cómo ayudar a las víctimas a recuperarse de los efectos del abuso desde un espacio pastoral de acompañamiento? ¡Esa es la tarea pendiente!

De todo el análisis bibliográfico que hemos realizado previamente en este mismo trabajo, podemos obtener algunas luces que guían las siguientes recomendaciones pastorales. Estas claves pueden ser de utilidad para poder acompañar los procesos de reelaboración existencial de la persona que ha sido abusada sexualmente y que desea reconciliarse en su interior, desde la sexualidad y en ella con Dios. De antemano sabemos que es una propuesta con límites, pues es poco probable que le ayude a una persona que se declara no creyente, por ejemplo. Sin embargo, dada la magnitud del problema, la necesidad de dar respuestas urgentes y adecuadas como Iglesia y por la profundidad que la fe puede ofrecer a un proceso de sanación integral, vale el esfuerzo de apuntar algunos detalles. Estas claves pastorales bien podríamos dividirlas en dos grupos: uno que tiene que ver más con las actitudes de acompańamiento y otro que está más relacionado con la ruta misma de reconciliación.

En cuanto las actitudes de acompañamiento, ya hemos reiterado que este proceso de reconciliación se debe ofrecer más como un horizonte que como una meta. Es fundamental que el acompañamiento sea respetuoso y que sea guiado por el acompañado. Como todo acompańamiento espiritual la sugerencia es 
que el acompańante practique la escucha activa en cuanto a estar presente, atento, listo para intervenir al momento justo, pero una escucha también pasiva en cuanto a no permitir que sean sus propias convicciones o creencias religiosas las que se impongan al acompañado, sino garantizar que sea este último quien protagonice su propio proceso.

Especialmente en acompañamiento a personas que han sido abusadas, se debe tener mucho cuidado con los prejuicios que se tenga a nivel sexual, pues esta es una de las dimensiones que merece mayor atención y que necesariamente se deberá trabajar. Ya habíamos reconocido la importancia de acompañar un proceso de reconciliación sexual sólido para poder ayudar a sanar la experiencia trascendente de la víctima. Es imposible "salvar" a una persona si no se salva su sexualidad. Es imposible sanar a una persona en su integridad si no se sana su cuerpo y su sexualidad. Entonces, el acompañante debe tener claridad sobre el valor trascendente de la sexualidad, conocer sus dimensiones, los niveles de su desarrollo, pero sobre todo ha de estar dispuesto a acompañar a la víctima hacia la recomposición de su dignidad, hacia la recuperación de los significados positivos que tiene la sexualidad para su vida.

A propósito también de las actitudes, el cardenal arzobispo de Manila, Monseñor Luis Antonio Tagle (2019), aportó con una intervención contundente en el encuentro La protección de los menores en la Iglesia. Por un lado, recordó nuestra responsabilidad como pastores, agentes de pastoral y cristianos en general de ser sanadores, y de asumir las consecuencias que esto conlleva: "debemos rechazar cualquier tendencia que (...) se niega a ver y tocar las heridas de los demás, esas heridas que son las heridas de Cristo en los heridos". Tocar las heridas es la primera actitud para acompañar la experiencia del resucitado, porque además, al tocar las heridas de aquellos que han sufrido la injusticia y la violencia estamos reconociendo nuestra responsabilidad en la herida que algunos hombres provocan a la propia humanidad. Ese, según Monseñor Tagle, es el primer paso hacia la reconciliación personal y social.

Se necesita al mismo tiempo un acompañamiento psicológico, dependiendo de la gravedad del trauma incluso psiquiátrico. No todos los acompañantes espirituales pueden ofrecer herramientas desde la psicología. Por lo tanto, hay que ser humildes en ello y dar paso a la intervención especializada si se requiere. Si la víctima ha sido una persona de fe, su conflicto interno requiere de ambos, de los psicólogos y de los acompañantes espirituales formados en el tema. Esta persona en camino de sanación necesita que sus acompañantes conozcan la fatalidad que significa el abuso para su existencia, que puedan empatizar con la historia de esa persona (Egas et al, 2018) que además sean capaces de entrar sin prejuicios y con generosidad en un proceso de acompańamiento largo y complejo. Todo esto sin olvidar que hace falta tomar todas las medidas legales de protección, de sanción, y de justicia- entendida en términos legales. El conflicto, recordemos, es interno y externo, por lo tanto las dos dimensiones exigen tratamiento.

Principalmente en lo que respecta al acompañamiento espiritual, el acompańante deberá ser capaz de proveerle incluso de experiencias relacionales adecuadas, plenificantes, reconciliantes, es decir, verdaderamente amorosas. Esto se puede lograr a través del mismo protocolo de acompañamiento. Cuanto más un acompañante se esmere en cuidar el encuentro con su acompañado, mejor este último comprenderá su valor como persona, su capacidad de relacionarse desde el amor, restaurando así su dignidad y su autoestima. El acompañante también deberá estar en la capacidad de conectarle con espacios donde esta persona pueda sanar su sexualidad a la luz de la Palabra, dentro de la comunidad eclesial, a través de los sacramentos, en último término, haciendo una experiencia espiritual profunda de reencuentro con su Creador, en Jesucristo. 
Si las actitudes del acompañamiento son un tema a cuidar, más aún son los contenidos de este peregrinaje. La hoja de ruta para la reconciliación sexual desde la profundidad de la fe cristiana no puede estar marcada por otra persona que no sea Jesús. Es en Jesucristo donde esa víctima se sentirá acompañada realmente, por Jesús vulnerado en la cruz injustamente, que clama al Padre en la hora del dolor, pero que, finalmente, le entrega su espíritu y al tercer día, resucita.

\author{
Dentro de tu grito en la cruz \\ caben todos nuestros gritos$$
\text { (...) }
$$ \\ Dentro de tu grito lanzado al cielo \\ encomiendan su vida en las manos del Padre \\ todos los que se sienten abandonados \\ en un misterio incomprensible. \\ Desde el desconcierto lanzado como queja \\ de los que experimentaron tu amor alguna vez, \\ pero se sienten abandonados ahora
}

(González, 2007)

Aquí debemos hacer esta referencia explícita. Si bien ya se ha dejado entrever los misterios divinos que sostienen la orientación de nuestra sexualidad hacia el amor (el de la Santísima Trinidad y el de la Encarnación), aquí se precisa tratar el misterio de la vida de Jesús que mejor acompaña e ilumina la experiencia de abuso y el proceso de sanación, a saber, el misterio de su Muerte y Resurrección. La venida de Jesucristo fue para anunciar que es posible reconciliar lo que hemos roto por el pecado, que podemos salvar lo que se ha perdido, y que ese volver a la "conciliación original" a la "unidad primera", es resucitar. Pero el resucitado es el mismo crucificado, su cuerpo quedará tatuado con las marcas de las heridas para siempre.

Algunos estudiosos del tema, como Tombs, proponen, por ejemplo, ayudar a las víctimas a contemplar el evento de abuso sexual en el contexto de la pasión de Cristo. Según la experiencia de campo del teólogo, esta sugerencia podría servir de ayuda práctica a las víctimas de tortura y abuso sexual. Para él, reconocer abuso sexual en el trato a Jesús podría traer una experiencia liberadora y sanadora a las personas que hayan sido abusadas, podría devolverles la dignidad y respeto hacia sí mismos. "Un Dios que, a través de Cristo, se identifica con los hambrientos, los sedientos, los forasteros, los que no tienen ropa, los enfermos y los presos (Mt. 25, 31-46) también puede identificarse con quienes sufren abuso y tortura en el mundo moderno" (Tombs, 2018, p. 109).

Esta es una propuesta muy interesante y atrevida. Aunque no estamos de acuerdo en todo con ella, la acotamos por la valía que según los autores sí ha demostrado tener para algunos sobrevivientes de abuso sexual. Como dice el fragmento de poema que hemos citado antes, en el grito de Jesús caben todos nuestros gritos, los de las víctimas de abuso sexual, y también los de las víctimas de las guerras, y los de las del holocausto... y así una lista interminable de víctimas de las violencias y de las injusticias contra la humanidad en cualquier tiempo.

Por nuestra fe sabemos que las vidas robadas por la violencia han sido acogidas por el Padre en la eternidad. Pero las vidas que quedan rotas y marcadas por la injusticia y la barbarie tienen por delante un 
camino doloroso y al mismo tiempo susceptible de ser también liberador. En el misterio de la Pasión, las víctimas en proceso de acompañamiento están llamadas a volver sus pasos sobre la historia que le marcó una vez de manera injusta y arbitraria. Esta vez, el regreso lo han de hacer con la libertad suficiente para salir de su rol de víctima, liberando a los otros de su rol de agresores. "Nadie me quita la vida, sino que yo la entrego" (Jn 10,18). Esta sería la invitación para el acompañado, a entregar su perdón como vía de liberación tanto para sí mismo como para quien fuera una vez su victimario.

El acto de amar al enemigo que tanto mal ha causado, ya es en sí mismo un acto de reconciliación, una muestra evidente de una sexualidad reconciliada, de una capacidad sorprendente de salir al encuentro amoroso y creativo del otro, es un acto que se vuelve sacramento del amor misericordioso de Dios encarnado en la vida de las víctimas que deciden dejar de su rol de víctimas para convertirse en sobreviviente de la masacre. De todos modos, vale aclarar que nuestra intención aquí no es ni menos hacer un tratado sobre moral sexual del abuso en el cual se justifique en modo alguno el hecho. El abuso sexual es un acto deplorable, es un pecado que trae consecuencias fatales y de por vida a la víctima, y es un delito.

Sabemos que perdonar, es el complemento justo para sanar un corazón que ha sido víctima de la injusticia. Si bien contar la verdad, tomar las medidas legales que garantizan una cierta justicia es importante. Pero no es suficiente. El camino del perdón es la forma quizá más efectiva para liberarse del peso que ha puesto el abuso en la espalda de sus víctimas. Contar con un horizonte de reconciliación es el camino de esperanza para dejar la posición de víctima y recuperar la condición de hijas e hijos de Dios en dignidad y libertad. Para ello, el sobreviviente ha de hacer un camino determinado de recibir de Dios el amor incondicional que reparte a todos, independientemente de las obras buenas que hayamos hecho, para que luego, una vez llenados de tanto amor gratuito, puedan dar el paso de amar en exceso, de perdonare, a aquellos que no lo merecen por sus propios actos pasados.

Cuando la víctima deja de mirar hacia la cruz como condenación perpetua, como injusticia inexplicable, y comienza a mirar hacia el sepulcro vacío como horizonte de esperanza, como certeza de resurrección... cuando su grito de queja y lamento ante la aparente ausencia de Dios se funde en un nuevo grito de confianza y entrega de la vida. Cuando esa persona, al estilo de los de Emaús, es capaz de volver sus pasos al lugar de la barbarie para compartir con los que allí quedaron la alegría de su encuentro con el Resucitado, la certeza de que es posible restaurarse, sanarse, entonces esa persona ya dejó de ser víctima de abuso sexual y ha comenzado su peregrinaje como sobreviviente reconciliado en su sexualidad.

La reconciliación, comprendida desde este misterio es sinónimo de resurrección. El resucitado es el mismo crucificado, su cuerpo glorioso puede mostrar la herida del costado, las llagas en las manos. El reconciliado es el mismo abusado... el sobreviviente es el mismo que una vez fue víctima. Su cuerpo, corazón, vida, sexualidad quedarán marcados, sí, pero es posible que esos "pedazos" en los que se partió la sexualidad, sean juntados nuevamente... como la piel abierta y sangrante por una herida, que después de muchas curas y cuidados se junta, se cierra, se sana... y queda la marca, pero ya no duele... Hacia allá apunta la reconciliación.

Nuestra mirada apunta a que la sexualidad no duela, que sea espacio de relación amorosa y generosa, plenificante, que sea dimensión digna de agradecimiento y puente de fraternidad verdadera. Este proceso, inspirado en su vínculo fundamental, la relación filial con Dios, cuyo amor es gratuito e incondicional será el mejor resultado de un proceso de acompañamiento espiritual: recuperar su condición original 
de hijo amado. Si una víctima logra experimentar nuevamente la alegría de ser hijo, y con gratitud es capaz de reconocer que es una persona digna en ese amor del Padre, entonces podemos decir que esa persona, que una vez fue víctima de abuso sexual se ha convertido en sobreviviente, en hombre nuevo, en mujer resucitada, y en su sexualidad, también se ha reconciliado. La misión, en adelante, será la de ser "embajadores de la reconciliación" $(2$ Cor 5,20$)$ para acompañar a otros en sus esfuerzos de comenzar a resucitar con Cristo.

\author{
En ese grito tuyo último, \\ dolor de hombre y dolor de Dios, \\ inclinamos agotados la cabeza \\ y te entregamos el espiritu \\ cuando llegamos a nuestros límites, \\ donde se extinguen los esfuerzos y los días \\ $y$ donde empezamos a resucitar contigo
}

(González,' 2007)

\title{
Conclusiones
}

El abuso sexual es un delito. Si es cometido contra un menor, el acto es aún más deplorable. Y también es un pecado de índole sexual que atenta contra la justicia y la caridad porque transgrede la dignidad de la persona violentada/agredida/abusada. Al ser un acto que agrede directamente la sexualidad de una persona, sus consecuencias repercuten negativamente en todas las demás dimensiones de su ser: psicológica, biológica, ético-social y espiritual-trascendente. Sus secuelas pueden ser, en muchas ocasiones, de carácter irreversible. El conflicto intrapersonal que experimenta una víctima de abuso sexual la desintegra, desequilibrando los significados positivos que esa persona puede tener sobre su propia identidad, su valor y sus capacidades de relación amorosa. En medio de esta realidad, llamamos experiencia de ruptura fundamental a la sensación que experimenta la víctima de haber perdido su dignidad y el sentido amoroso de su existencia.

La reconciliación sexual no se refiere al sacramento de la confesión/ penitencia/ reconciliación en tanto no es una invitación a arrepentirse del pecado, sino que es la invitación a un proceso más profundo de reconstrucción, recomposición, y sanación existencial. Desde su etimología, reconciliación quiere decir volver a establecer relaciones justas entre aquellas partes que han sido separadas. En el caso de una víctima de abuso sexual asumimos que el conflicto interior causa una especie de desintegración del ser (como es un ser sexuado, también desintegración en su sexualidad) cuyas "partes" están llamadas a la reconciliación.

Desde la fe, esta reconciliación implica restablecer la relación “justa” con Dios en primera instancia. El calificativo de justa, en este caso, radica en "hacer justicia" con lo que somos fundamentalmente, hijos amados de Dios, imagen y semejanza suya. Este primer momento de reencuentro con el vínculo fundante del amor incondicional de Dios impulsaría un segundo momento de reencuentro y reconstrucción de la propia dignidad de la persona en su cuerpo y en todas sus dimensiones. 
La sexualidad, al ser un aspecto presente y operante en todas las dimensiones de la persona, es una dimensión intrínsecamente conectada con estas dimensiones; por lo tanto, lo que afecte a cualquiera de estos ámbitos (biofísico, psicológico y afectivo, hasta el ético y espiritual) afectará necesariamente a la sexualidad, y viceversa. Consecuentemente, para poder sanar a nivel psicológico o a nivel espiritual, es necesario sanar también a nivel sexual. La reconciliación sexual, como proceso de transformación positiva intrapersonal es un proceso siempre integral con consecuencias efectivas para la restauración psicológica y espiritual de una persona.

En el itinerario para alcanzar una sexualidad reconciliada se deben tener en cuenta las dimensiones de la sexualidad (instintiva, humana y teológica) y sus tres niveles (genital, psicológico y dialógico/social) para iluminar cada uno de ellos con la dignidad propia de los hijos de Dios, creados por, en y para el amor. La sexualidad marca el modo de relacionarse con los otros y con Dios. Su finalidad última es el amor. Si no se recupera la sexualidad de una persona herida por la violencia del abuso sexual, su capacidad de relacionarse amorosamente a nivel interpersonal y trascendente, tampoco se restaura. Por esta razón, hablar y trabajar por una sexualidad reconciliada en un contexto eclesial constituye una tarea urgente y necesaria.

La reelaboración existencial del sobreviviente de $\mathrm{fe}^{11}$ necesita, en primer lugar una reconciliación espiritual honda, para, desde aquí, poder recuperar el sentido original de su sexualidad. Para la persona cristiana especialmente, Jesucristo sigue siendo el modelo a seguir. La invitación de Jesús a lo largo de la vida es siempre volver sobre esa experiencia primera y fundante del amor paterno, del amor incondicional, gratuito, e infinito de Dios por cada una de sus criaturas, que Él mismo hubiera experimentado a orillas del río Jordán.

"En Jesús experimentamos la misericordia que protege la justicia y celebra el gran regalo de perdón" (Tagle, 2019) por ello tenemos la esperanza de convertirnos, como Iglesia, cuerpo de Cristo, en una comunidad de justicia que entra en comunión con las heridas del mundo, que se compadece y que es capaz de ser "embajadora de la reconciliación" (2Co 5, 20), capaz de acompañar la experiencia del resucitado que se acerca con sus heridas y nos dice “iLa paz esté con ustedes!”.

\section{Referencias}

AA.VV. (1993). Nuevo diccionario de Teología Moral. Voz: Sexualidad, pp.1681-1697. Ediciones Paulinas

AA.VV. (2016). Los gritos de mi silencio, violencia y abuso sexual en la infancia (primera ed. digital, Vol. 1). Madrid epubspain.com. Recuperado a de www.bi-bliotecadesaludmentalcom

11 Esto porque hablamos estrictamente de acompañamiento espiritual cristiano. Sin embargo, los mismos acompañantes espirituales que han trabajado durante años en el acompańamiento a sobrevivientes de abuso sexual pueden corroborar la certeza de que el camino cristiano de reconciliación con Dios como fuente de fuente de vida plena y plenificante, es un camino universal, válido también para los no creyentes. Quien dijere que no cree en un Dios Creador, también ha de necesitar una fuente de amor si no infinita y gratuita al menos suficientemente grande y sólida, capaz de sostener sus autoconcepciones sobre sí mismos, sobre su sexualidad, sobre sus valores. Esto se puede traducir en experiencias concretas de perdón, de amor incondicional de parte de otras personas que bien pueden ser amigos o familiares. 
Baita, S., \& Moreno, P. (2015). Abuso sexual infantil, cuestiones relevantes para su tratamiento en la justicia (Primera). Mastergraf. Montevideo, Uruguay.

Benedicto XVI (2010). Carta pastoral del Santo Padre a los católicos de Irlanda. (19 de marzo, Solemnidad de San José). Recuperado de http://w2.vatican.va/content/be-nedict-xvi/es/letters/2010/documents/hf_benxvi_let_20100319_church-ireland.html

Biblia de Jerusalén. Nueva edición totalmente revisada. (2018).

Bloomfield, D. (2006) On Good Terms: Clarifying Reconciliation. Berghof Report No.14. Berghof Research Center for Constructive Conflict Managment, Berlin.

Botero, S. (2012). Hacia una antropología teológica de la sexualidad. En búsqueda de una nueva comprensión. Editorial San Pablo.

Cahill, L. y McEvenue,S. (1998). El significado general de la sexualidad en la Biblia, Revista Bíblica (60) 196, 48.

Cerón-Hernández, G., Roa-Torres, S., \& Salcedo-Cifuentes, M. (2017). Caracterización de los casos de abuso sexual valorados en los servicios de urgencias y consulta externa de una institución hospitalaria de primer nivel en el Departamento del Cauca, 2007-2015. Universidady Salud, 19 (2), 226-236. https://doi.org/10.22267/ rus. 171902.85

Coello, C. (2017). Por cada caso denunciado de abuso sexual a menores hay otros 5 ocultos. Redacción médica, Recuperado de https://www.redaccionmedica.ec/-secciones/salud-publica/por-cada-casodenunciado-de-abusosexual-a-menores-hay-otros-5-ocultos-89644

Consejo Pontificio para la Familia. (1996). Sexualidad humana: verdad y significado: Orientaciones educativas en la familia (Vol. 8). Palabra.

Demasure, K. \& Joulain, S. (s/f). 2. Términos y definiciones. Texto base de la unidad 2 del Programa de Formación de Tutores en la Prevención del abuso Sexual de niñas, niños y adolescentes.

Diario El Comercio. (2018). La sanción contra el abuso sexual a los niños cambió. Redacción del 9 de febrero de 2018.

Egas-Reyes, V., Barahona-Cruz, P., Ordónez, D., Grijalva, V., Man Ging, C. (2018). Evaluando la importancia de la empatía en la prevención del abuso sexual en niñas, niños y adolescentes, Libro de Memorias de VI Congreso de la Red Ecuatoriana de Universidades y Escuelas Politécnicas para la Investigación y Postgrados

Entralgo, L (1961) Enfermedad y pecado. Barcelona, Toray, 1961, 125 pp.

Figueroa, R. \& Tombs, D. (2019). Reconociendo a Jesús como víctima de abuso sexual: respuestas de sobrevivientes del Sodalicio en el Perú. Centro de Teología y Asuntos Públicos, Universidad de Otago

Finkelhor, D. (1986). (Ed.). A Sourcebook on child sexual abuse. Beverly Hills, London, Sage Publications: New Delhi. https://doi.org/10.2307/583557

Finkelhor, D., \& Browne, A. (1986). Initial and long-term effects: A conceptual framework. En: D. Finkelhor (Ed.). A Sourcebook on child sexual abuse. Beverly Hills, Sage Publications: London, New Delhi

Francisco (2019). Discurso del Santo Padre al final de la concelebración eucarística del Encuentro La protección de los menores en la Iglesia (24 de febrero). Ciudad del Vaticano.

Francisco, P. (2016). Exhortación Apostólica Postsinodal Amoris Laetitia. Ciudad del Vaticano: Librería Editorial vaticana. 
Francisco. (2016). Exhortación apostólica postsinodal Amoris Laetitia, sobre el amor en la familia. Librería Editrice Vaticana: Ciudad del Vaticano.

Galtung, J. (1998). Tras la violencia, 3R: reconstrucción, reconciliación, resolución. Bakeas.

González, B. (2007). "El Grito de toda la Historia”, en Salmos para "sentir y gustar internamente”. Una ayuda para la experiencia de los Ejercicios Espirituales. Sal Terrae.

Gre Altermatt, M. J. (2019). Las dinámicas de estigmatización del abuso sexual: Experiencias de revelación de mujeres victimizadas en la infancia.

Hernández, J. C. G. (2008). El museo como lugar de presentación de la historia: donación, apropiación y testimonio. In I Congreso Colombiano de Filosofía-Estética, fenomenología y hermenéutica-Volumen I (p. 147). Universidad Jorge Tadeo Lozano.

Hernández Maldonado, E. (2016). Violencia contra las mujeres: un estudio sobre los dispositivos de atención disponibles en Montevideo, Uruguay.

Iglesia Católica Conferencia Episcopal Panameña. (2006). Catecismo de la Iglesia Católica: compendio. Editorial San Pablo.

Loidi, P. (2005). Creer como adultos. Verbo Divino. En: Botero (2012) Hacia una antropología teológica de la sexualidad. En búsqueda de una nueva comprensión. Editorial San Pablo.

López Ochoa, M. A., \& Poma Quito, J. A. (2007). Evaluación psicológica en niños/as de 5 a 10 años víctimas de abuso sexual estudio realizado en la corporación mujer a mujer durante el periodo abril-octubre 2005 (Tesis de licenciatura, Universidad del Azuay).

López, E. (2001). Simbolismo de la sexualidad humana. Criterios para una ética sexual. Sal Terrae

López, F. (2014). Los abusos sexuales a menores y otras formas de maltrato sexual. Editorial Síntesis. SA. Madrid, España.

López, F. (e). (2009). Investigación sobre abuso sexual a niñas, niños y adolescentes en el Ecuador. Informe 2009. Defensa de los Niños Internacional-DNI Ecuador

López, S. V. (2012). A propósito de la Teología del Cuerpo. Cuestiones teológicas, 39(91), ISSN 0120-131X.

Man-Ging, C. (2019). Hacia una cultura de la prevención del abuso sexual en la Iglesia Católica. México: PPC ISBN 978-84-288-3475-9

Man-Ging, C. I., Böhm, B., Fuchs, K. A., Witte, S., \& Frick, E. (2015). Improving empathy in the prevention of sexual abuse against children and youngsters. Journal of child sexual abuse, 24(7), 796-815. https://doi.or $\mathrm{g} / 10.1080 / 10538712.2015 .1077366$

Merlyn, M. (2005). La problemática del abuso sexual en niños y adolescentes. Panorama general y situación en Ecuador. Centro de Publicaciones PUCE, Quito, Ecuador

Molina Cadena, L. S. (2018). Aceptación incondicional positiva para promover resiliencia en niños víctimas de abuso sexual (Tesis de licenciatura, Quito).

Muñoz Ayala, R. A. (2014). De la filiación a la paternidad: un proceso de reconciliación interior meditando” El regreso del hijo pródigo de Rembrandt” por Henri Nouwen. (Tesis de Magister, Universidad Alberto Hurtado, Santiago).

Navarro, R. E. (2015). De lo humano vulnerado a lo humano resignificado: Desde la experiencia espiritual de Etty Hillesum. Cuestiones Teológicas, 42(97), 205, ISSN 0120-131X 
Odriozola, E. E., de Corral Gargallo, P., \& Andrés, P. J. A. (2004). Evaluación del daño psicológico en las víctimas de delitos violentos. Psicopatología Clinica Legal y Forense, 4(1), 227-244.

Organización Mundial de la Salud (2002). World report on violence and health. Geneva: Autor.

Organización Mundial de la Salud (Ed.). (2002). Informe mundial sobre la violencia y la salud: sinopsis. OMS.

Organización Mundial de la Salud (Ed.). (2016). Comprender y abordar la violencia contra las mujeres. OMS

Pfürtner, S. (1975). La chiesa e la sessualita冈. Bompiani. Milano. En: Botero (2012) Hacia una antropología teológica de la sexualidad. En búsqueda de una nueva comprensión. Editorial San Pablo.

Ponce, F. (febrero de 2018). La Reconciliación nos complica la vida. Palabras de Inauguración en el Conversatorio Del conflicto a la reconciliación llevado a cabo en la Pontificia Universidad Católica del Ecuador, Quito.

Ponce, I. (2018). El silencio más grande de todos los de Ecuador. Historias en GK City, Ecuador. Recuperado de http:// ser-nina.org/el-silencio-mas-grande-de-todos-los-del-ecuador/

Rahner, K. (1964). Iglesia y Sacramentos. Editorial Herder S.A, Barcelona, España, pp. 100-103.

Real Academia Española. (2014). Diccionario de la lengua española, 23. Asociación de Academias de la lengua española. Voz: reconciliación.

Rodríguez González, M., Arteaga Ramírez, I., \& Rodríguez González, O. (2014). Caracterización de conducta sexual inadecuada hacia niños y adolescentes. MediSur, 12(2), 398-407.

Sánchez-Girón Renedo, J. L. (2020). Sanciones en la Iglesia y Procesos. Comillas: Madrid.

Tagle, L. (2019). Conocer el dolor y curar sus heridas es el corazón de la tarea del pastor. Intervención en el Encuentro La protección de menores en la Iglesia, Ciudad del Vaticano, 21 de febrero. Recuperado de https:// iglesiaactualidad.wordpress.com/-2019/02/21/intervencion-del-cardenal-luis-antonio-tagle-en-el-encuentrosobre-la-proteccion-de-los-menores-en-la-iglesia/

Tombs, D. (2018). Crucifixión, terrorismo de Estado y abuso sexual: Texto y Contexto. Union Seminary Quarterly Review, (53) pp. 89-109.

UNICEF Ecuador (2017). Dossier informativo sobre la campaña \#AhoraQueLoVes \#DiNoMás. Recuperado de https://www.unicef.org/ecuador/media/1191/file-/Dossier\%20informativo\%20sobre\%20la\%20 сатра\%С3\%B1a\%20\#AhoraQueLoVes\%20\#DiNoM\%C3\%A1s.pdf

Urra, J. (2007). SOS... Victima de abusos sexuales. Ediciones Pirámide (Grupo Anaya, S.A) Madrid.

Vidal, M. (1971). Moral de actitudes: moral del amor y de la sexualidad. Sígueme: Salamanca

Wambra (2018). Las niñas invisibles de Ecuador. Publicado el 6 de marzo de 2018 por Ana Acosta y Luisana Aguilar. Recuperado de: https://wambra.ec/las-ninas-invisibles-ecuador/

Wilson, D. (2010). Health consequences of childhood sexual abuse. Perspectives in Psychiatric Care, (46), pp. 5664. https://doi.org/10.1111/j.1744-6163.2009.00238.x 